\title{
POTENCIAL EROSIVO DE SOLOS TROPICAIS A PARTIR DE ENSAIOS GEOTÉCNICOS DE AVALIAÇÃO DIRETA E INDIRETA
}

\author{
EROSIVE POTENTIAL OF TROPICAL SOILS USING GEOTECHNICAL TESTS FOR DIRECT \\ AND INDIRECT EVALUATION
}

\section{Taciano Oliveira da SILVA, Heraldo Nunes PITANGA, Sérgio Leandro Scher DIAS NETO, Roberto Lopes FERRAZ, Brahmani Sidhartha Tibúrcio PAES \\ Universidade Federal de Viçosa. Avenida Peter Henry Rolfs, s/n - Campus Universitário, Viçosa - MG. \\ E-mails: taciano.silva@ufv.br; heraldo.pitanga@ufv.br; sergio.scher.7@gmail.com; rlferraz@ufv.br; brahmani@live.com}

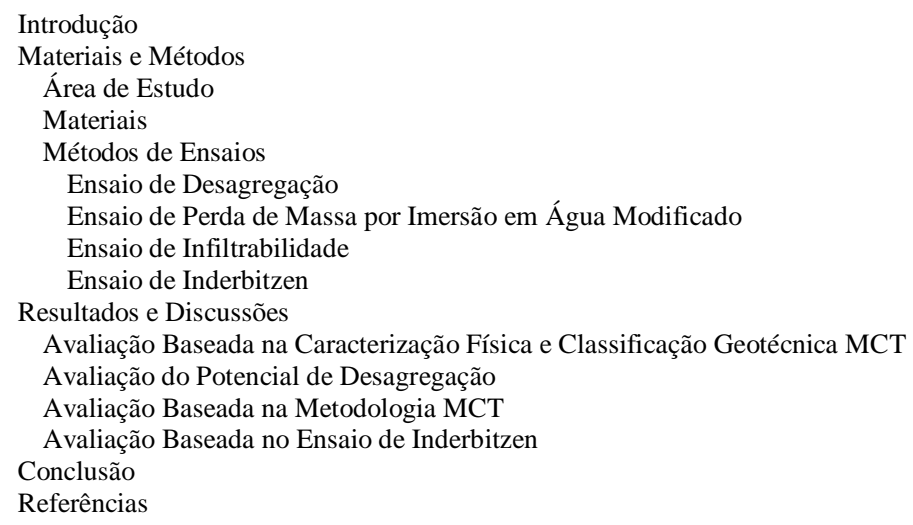

\begin{abstract}
RESUMO - Esta pesquisa refere-se à avaliação do potencial de erodibilidade de solos tropicais a partir de ensaios geotécnicos de avaliação direta e indireta. O programa experimental dessa pesquisa foi composto dos seguintes ensaios de laboratório: ensaios de desagregação, ensaios da metodologia MCT (ensaio de perda de massa por imersão em água modificado e ensaio de infiltrabilidade) e o ensaio de Inderbitzen. A avaliação direta, por meio do ensaio de Inderbitzen, foi a que melhor representou o comportamento erosivo dos solos e permitiu estabelecer uma hierarquia quanto ao potencial de erodibilidade das amostras analisadas. As avaliações indiretas, pelo ensaio de desagregação ou os da metodologia MCT, não foram suficientes para estabelecer uma ordenação do potencial de erodibilidade das amostras de solos analisadas. Porém, quando combinados, o ensaio de desagregação e os da metodologia MCT são recomendados como critérios preliminares na avaliação do potencial de erodibilidade de solos. Dessa forma, para maior detalhamento e confiabilidade na previsão do potencial de erodibilidade de amostras de solos de horizontes pedológicos de perfis de corte, recomendase a utilização do método direto de avaliação por meio do ensaio de Inderbitzen.
\end{abstract}

Palavras-chave: Solos tropicais; Erodibilidade; Ensaios geotécnicos.

ABSTRACT - This study assessed the erodibility potential of tropical soils using geotechnical test for direct and indirect evaluation. The experimental program of this research consisted of the following laboratory tests: slaking tests, MCT (modified water immersion mass loss tests and infiltrability tests) and Inderbitzen tests. The direct assessment, through the Inderbitzen test, was the one that best represented the erosive behavior of the soils and allowed to establish a hierarchy as to the potential erodibility of the analyzed samples. The indirect assessments, by the slaking test or those of the MCT methodology, were not enough to set a classification of the potential erodibility of the soil samples analyzed. However, when combined, the slaking test and those of the MCT methodology are recommended as preliminary criteria in the evaluation of soil erodibility potential. Thus, for further detail and reliability in the prediction of soil erodibility potential of soil samples from pedological horizons of cutting profiles, it is recommended to use the direct method of evaluation through the Inderbitzen test.

Keywords: Tropical soils; Erodibility; Geotechnical tests.

\section{INTRODUÇÃO}

A constante ocorrência de problemas derivados da evolução de processos erosivos associados a obras de engenharia, tais como a execução de perfis de cortes rodoviários e obras de drenagem para coleta e transporte de águas pluviais em vias urbanas e rurais, aponta a necessidade de identificação da susceptibilidade à erosão de terrenos através de critérios que levem em consideração as propriedades geotécnicas envolvidas nesse processo, em especial a erodibilidade de solos residuais tropicais.

Sob o enfoque geotécnico, a susceptibilidade aos processos erosivos pode ser caracterizada e mensurada por meio de métodos de análise direta e indireta que, sozinhos ou combinados, têm sido empregados para a avaliação da erodibilidade de solos tropicais (Bastos et al., 2001).

Bastos et al. (2000) afirmam que, dentre os ensaios geotécnicos para a determinação de 
erodibilidade em solo, os de Inderbitzen e de desagregação (métodos de avaliação direta e indireta de erodibilidade em solos, respectivamente) destacam-se pelo potencial de aplicação na previsão da erodibilidade de solos tropicais. Esses autores também mencionam a relevância do direcionamento apresentado pela metodologia MCT (Miniatura, Compactado, Tropical) ao considerar as peculiaridades dos solos e os ambientes tropicais úmidos na avaliação indireta da erodibilidade.

Ainda nesse contexto, Almeida et al. (2015) analisaram o efeito da sucção na erodibilidade de dois solos residuais localizados nas proximidades do município de Goiânia, no estado de Goiás, Brasil, por meio dos ensaios de Inderbitzen e de desagregação, constatando que as amostras com menores valores de sucção inicial apresentaram-se mais resistentes à erodibilidade superficial e à instabilidade quando inundados.

Este comportamento também foi observado por Fonseca et al. (2016) para amostras de solos residuais do município de Juiz de Fora, Minas Gerais, Brasil, por meio de ensaio geotécnico de erodibilidade de Inderbitzen.

Os critérios de avaliação indireta apresentados por Nogami \& Villibor (1995) com base nos ensaios da metodologia MCT mostraram-se eficientes na identificação dos diferentes potenciais de erodibilidade de amostras de solos residuais analisados por Menezes \& Pejon (2010) no interior do Estado de São Paulo, Brasil. Os referidos autores verificaram uma tendência do aumento de perda de massa por imersão e, consequentemente, um aumento da erodibilidade, quanto menor era $\mathrm{o}$ teor de umidade inicialmente imposto às amostras de solo investigadas.

No caminho inverso, Silva et al. (2015), para solos residuais da região do Alto Paraopeba, no
Estado de Minas Gerais, Brasil, observaram uma maior erodibilidade em amostras de solos residuais nas condições de umidade natural e préumedecida do que na condição seca ao ar. Esses autores destacaram que os critérios apresentados, com base nos ensaios de infiltrabilidade e perda de massa por imersão da metodologia MCT, são essenciais para uma avaliação mais detalhada do potencial de erodibilidade de solos tropicais, pois levam em consideração a infiltração da água através do corpo de prova e o efeito da secagem sobre o comportamento de amostras de solo inundadas.

Apesar de os ensaios da metodologia MCT apresentarem ampla aplicação na previsão da erodibilidade de solos tropicais, não permitem, assim como o ensaio de desagregação, estabelecer uma relação entre os resultados obtidos e níveis intermediários de erodibilidade. O ensaio de Inderbitzen supera essa limitação ao relacionar as perdas acumuladas de solo à resistência à erodibilidade, e destaca-se pela sua simplicidade de execução e por simular em condições próximas às reais como o solo se comporta frente a um fluxo superficial de água. Em contrapartida, esse ensaio não leva em consideração a infiltração de água através dos corpos de prova, aspecto muito importante nos processos erosivos em solos de clima tropical.

A contribuição técnico-científica da utilização de ensaios geotécnicos de avaliação direta e indireta consiste na tentativa de se estabelecer um novo direcionamento para a avaliação da potencialidade de erodibilidade de solos tropicais, visando à identificação e previsão de áreas mais propensas à ocorrência de processos erosivos.

Diante do exposto, o objetivo dessa pesquisa é avaliar o potencial erosivo de solos tropicais a partir de ensaios geotécnicos de avaliação direta e indireta.

\section{MATERIAIS E MÉTODOS}

\section{Área de Estudo}

A área adotada para o estudo consiste em um corte rodoviário, cujo perfil é formado por camadas de solos residuais originados de rocha gnáissica, localizado às margens da BR 120, nas proximidades do aeroporto do município de Viçosa, Estado de Minas Gerais, Brasil, com coordenadas geográficas de Latitude (2045'19,80’S), Longitude (4250’26,30’W) e Altitude média de, aproximadamente, $669 \mathrm{~m}$
(Figura 1).

No corte rodoviário, o perfil de solo se apresenta composto por três horizontes pedológicos em níveis distintos de processo erosivo, os quais foram designados por BR120-A, BR120-B e BR120-C, conforme apresentado na figura 2.

\section{Materiais}

Após a seleção da área de estudo, procedeu-se a coleta das amostras, as quais foram denominadas conforme o horizonte pedológico de origem, da 

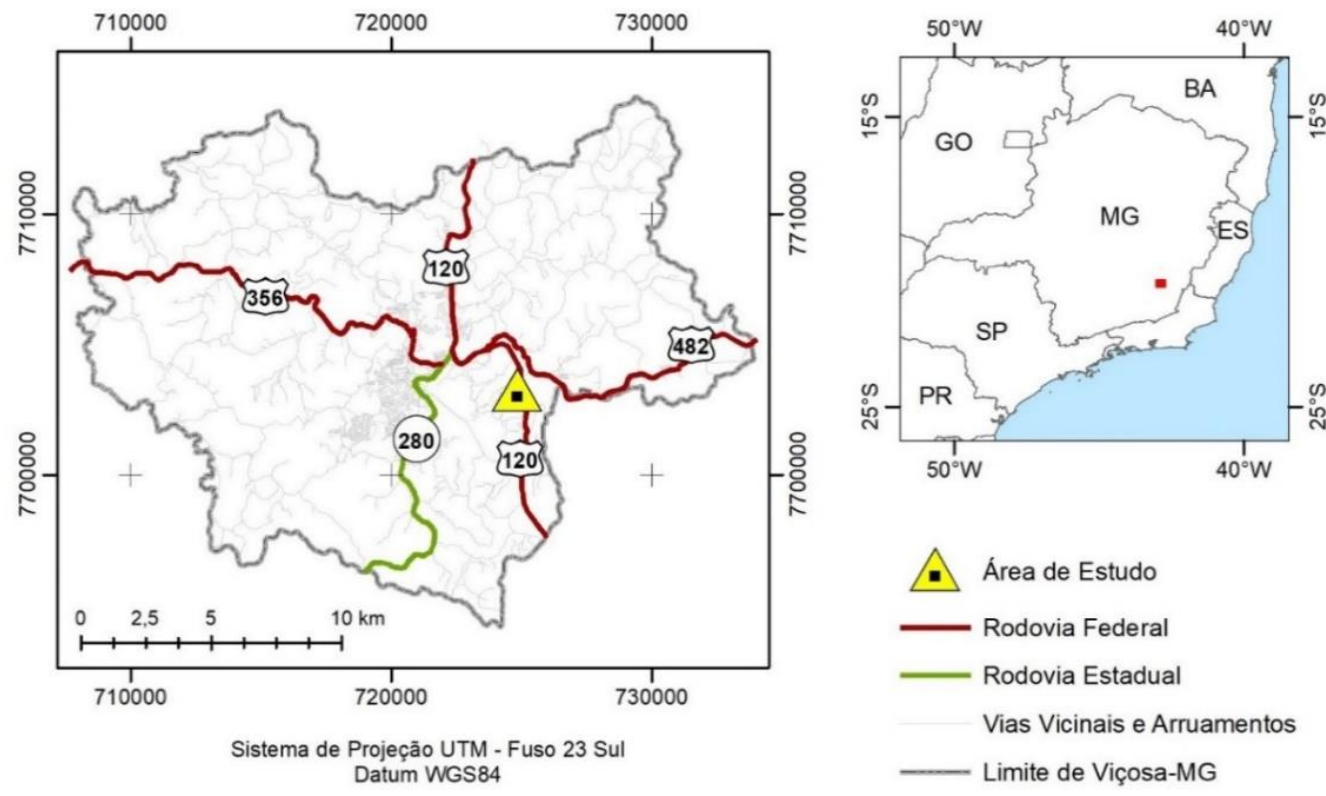

Figura 1 - Mapa de localização da área de estudo.
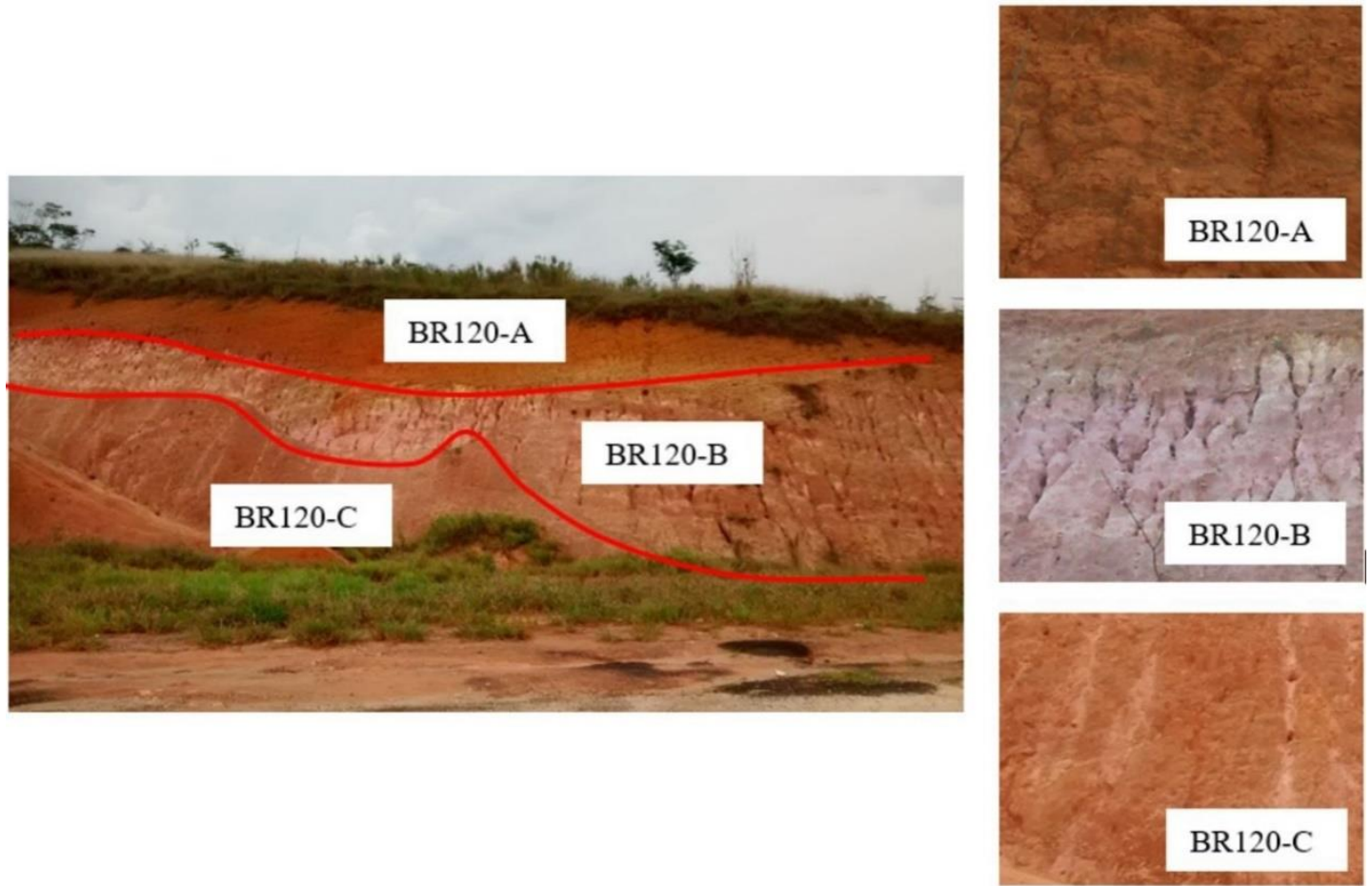

Figura 2 - Perfil de solos residuais e identificação de seus respectivos horizontes pedológicos.

seguinte forma: amostra BR120-A, amostra BR120-B e amostra BR120-C.

Em cada horizonte, foram coletadas as amostras deformadas e indeformadas conforme os procedimentos PRO 002 (DNER, 1994a) e PRO 003 (DNER, 1994b), respectivamente. Em seguida, essas amostras foram adequadamente identificadas e acondicionadas para a realização dos procedimentos experimentais.

\section{Métodos de Ensaios}

Para a caracterização física das amostras de solos analisadas, foram realizados os seguintes ensaios de laboratório: (a) análise granulométrica conjunta - NBR 7181 (ABNT, 2016a); (b) limites de Atterberg: limite de liquidez (LL) - NBR 6459 (ABNT, 2016b) e limite de plasticidade (LP) NBR 7180 (ABNT, 2016c); e (c) massa específica real dos grãos - NBR 6458 (ABNT, 2016d). As amostras deformadas de solo foram preparadas para os referidos ensaios de acordo com a norma técnica NBR 6457 (ABNT, 2016e). A classificação geotécnica de solos tropicais de acordo com a metodologia MCT, descrita na norma técnica CLA 259 (DNER, 1996), é realizada a partir dos resultados dos ensaios de compactação dinâmica mini-MCV - método de ensaio ME 258 (DNER, 1994c) e de perda de massa por imersão em água método de ensaio ME 256 (DNER, 1994d). 
Para avaliação indireta da erodibilidade, foram realizados os ensaios da metodologia MCT (perda de massa por imersão em água modificado e infiltrabilidade) conforme Nogami \& Villibor (1995) e o ensaio de desagregação conforme recomendações de Santos (1997). Para a avaliação direta da erodibilidade foram realizados os procedimentos apresentados por Inderbitzen (1961), utilizando-se do equipamento desenvolvido e adaptado por Stephan (2010).

\section{Ensaio de Desagregação}

Os ensaios de desagregação foram realizados conforme proposto por Santos (1997). Corpos de prova indeformados cilíndricos com $10,0 \mathrm{~cm}$ de diâmetro e 5,0 cm de altura foram moldados com o auxílio de anéis biselados de PVC e condicionados a três situações distintas de umidade: (a) umidade

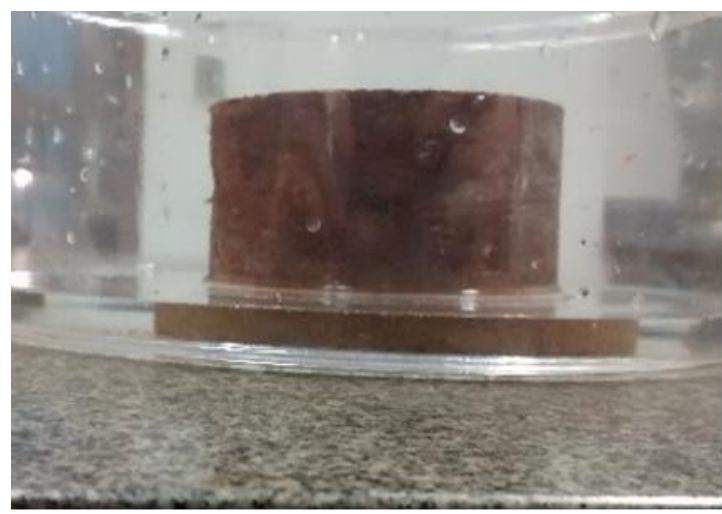

(a) nível d'água na base do corpo de prova, por 30 minutos

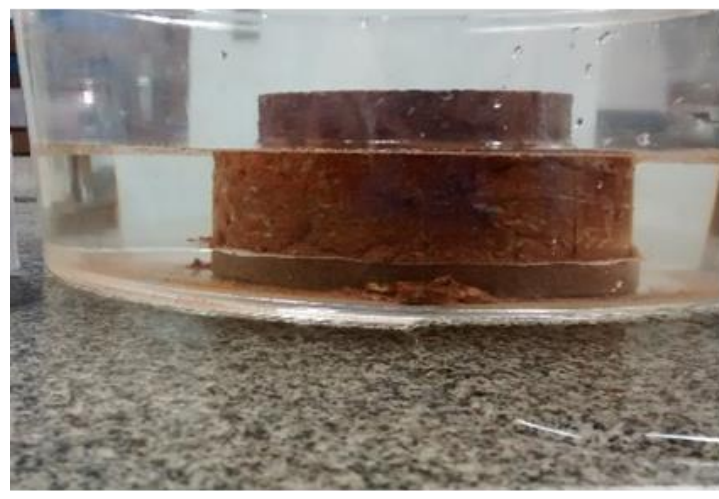

(c) nível d'água a 2/3 do corpo de prova, por 15 minutos natural; (b) seca ao ar (por, no mínimo, 72 horas) e inundada (por, no mínimo, 30 minutos).

Cuidadosamente, os corpos de prova foram retiradas dos anéis de PVC e dispostos sobre papel filtro e pedra porosa e submetidas a um processo lento de submersão em água, conforme apresentado na figura 3 , de acordo com os seguintes estágios:

i) Com o nível d'água na base do corpo de prova, por 30 minutos, conforme apresentado na figura $3 \mathrm{a}$;

ii) Com o nível d'água a $1 / 3$ e $2 / 3$ do corpo de prova, por períodos de 15 minutos, conforme apresentado nas figuras $3 \mathrm{~b}$ e $3 \mathrm{c}$; $\mathrm{e}$

iii) Com a submersão total do corpo de prova, permanecendo por 24 horas, conforme apresentado na figura $3 \mathrm{~d}$.

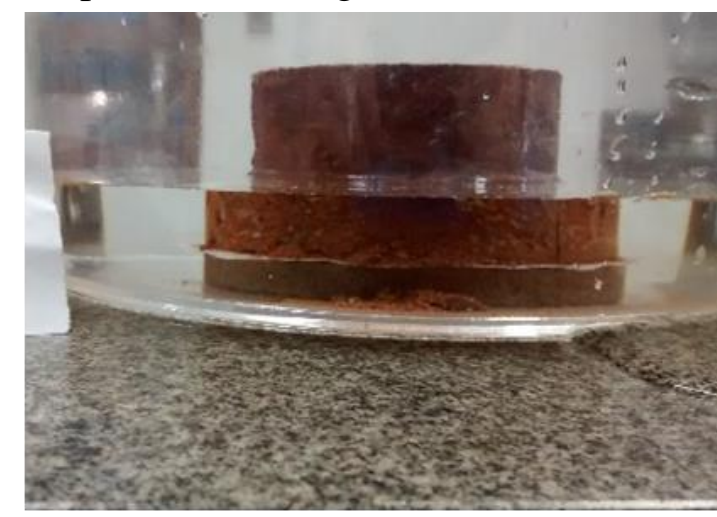

(b) nível d'água a $1 / 3$ do corpo de prova, por 15 minutos

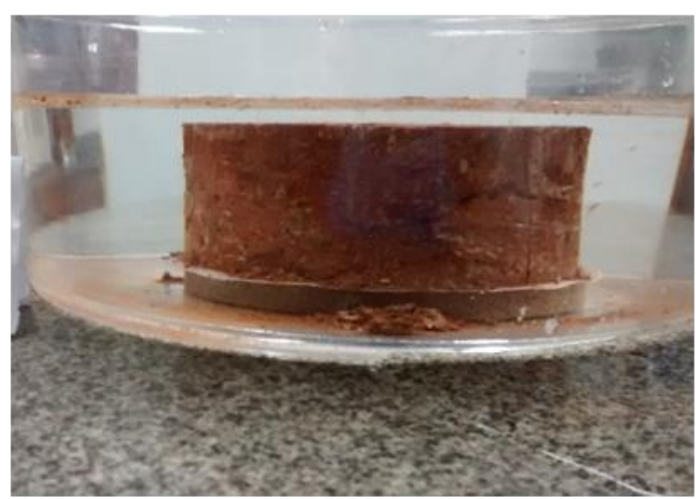

(d) submersão total do corpo de prova, permanecendo por 24 horas

Figura 3 - Etapas de submersão dos corpos de prova para o ensaio de desagregação.

Ensaio de Perda de Massa por Imersão em Água Modificado

Para a realização do ensaio de perda de massa por imersão modificado, utilizou-se do método proposto pela metodologia MCT, conforme Nogami \& Villibor (1995). Assim, foram utilizadas amostras indeformadas de solo dos horizontes pedológicos do perfil analisado, confinadas em anéis cilíndricos de PVC, com dimensões semelhantes àquelas estabelecidas originalmente pela metodologia MCT, conforme recomendações do método de ensaio ME 256 (DNER, 1994c), diferenciando-se deste pela redução das alturas dos corpos de prova de $5,0 \mathrm{~cm}$ para $2,5 \mathrm{~cm}$.

Os corpos de prova permaneceram submersos em reservatório com água durante um período 
mínimo de 20 horas e todo o material desagregado foi coletado em cápsulas posicionadas abaixo dos corpos de prova, conforme a figura 4 .

Ao fim do ensaio, o material coletado nas cápsulas foi levado à estufa para determinação da massa seca desprendida. Esse valor em relação à massa total de solo seco do corpo de prova equivale à perda de massa por imersão (pi em \%).

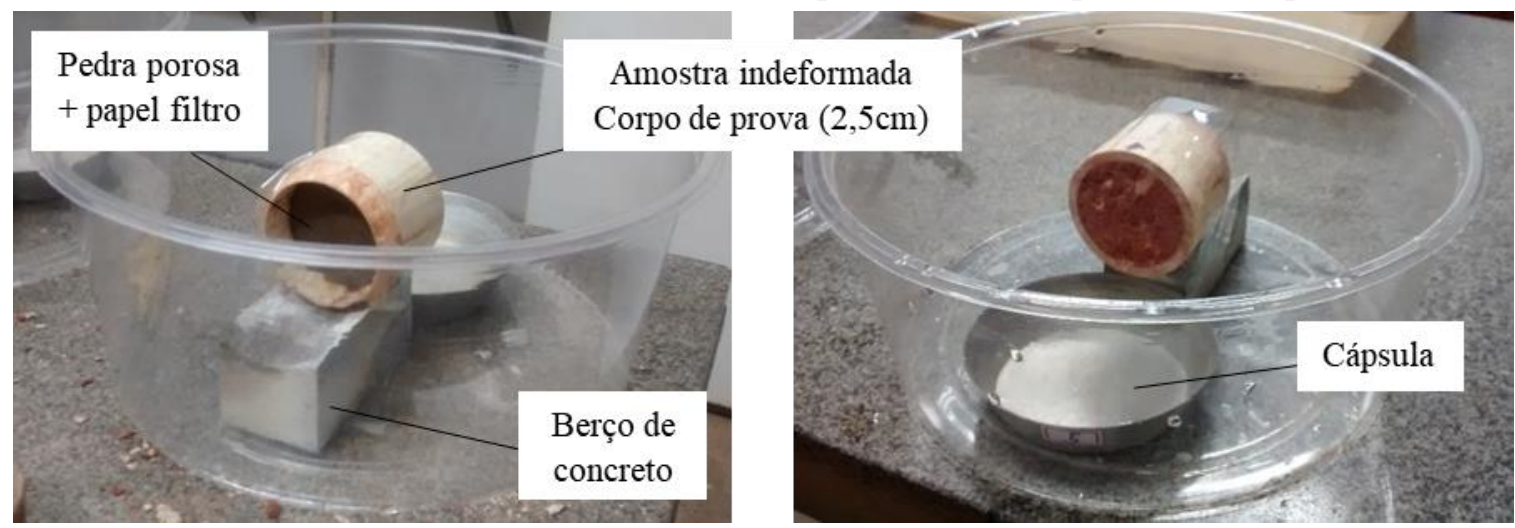

Figura 4 - Ensaio de perda de massa por imersão modificado.

\section{Ensaio de Infiltrabilidade}

Para a realização do ensaio de infiltrabilidade, utilizou-se do método da Metodologia MCT, proposto por Nogami \& Villibor (1995). Assim, foram utilizadas amostras indeformadas de solo, nas condições de umidade natural e seca ao ar (por, no mínimo, 72 horas), confinadas em anéis cilíndricos de PVC com 5,0 cm de altura e 5,0 cm de diâmetro.

O equipamento para realização do ensaio, conforme ilustrado na figura 5 , consiste em um

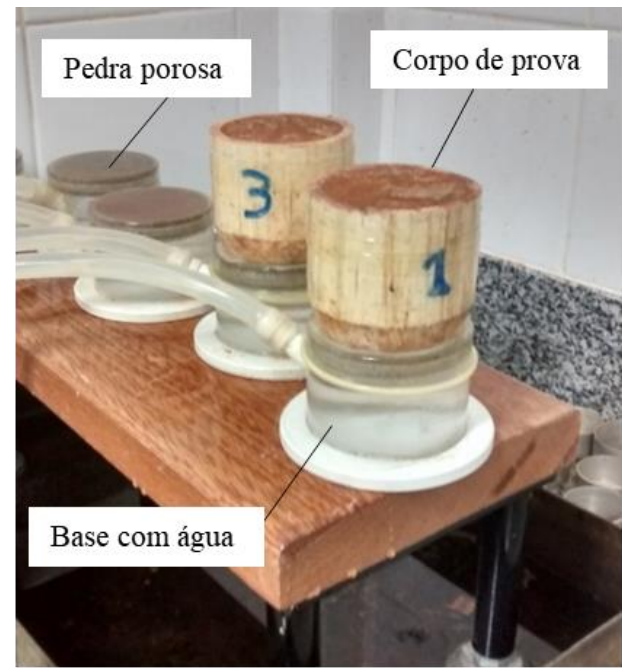

(a) Corpo de prova sobre a pedra porosa e o reservatório de água plano de madeira onde existem acoplados réguas graduadas e tubos capilares de vidro com $6,0 \mathrm{~mm}$ de diâmetro.

Estes estão ligados a um reservatório composto por pedra porosa de granulação aberta com topo livre, sobre as quais foram colocadas as respectivas amostras de solo. O tubo capilar é preenchido por água até que se extravase o topo do reservatório da pedra porosa a fim de garantir a correta quantificação do volume de água infiltrado nas amostras analisadas.

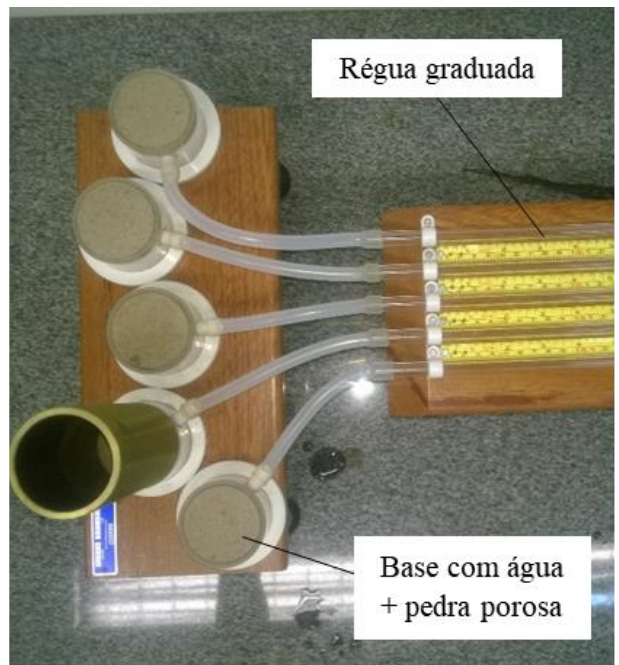

(b) disposição dos reservatórios de água

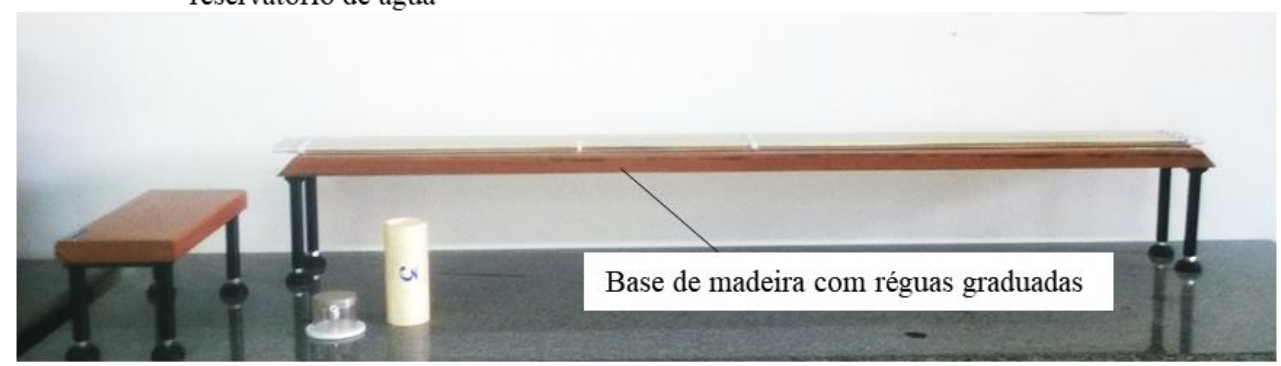

(c) Tubos capilares acoplados a uma base de madeira com régua graduada

Figura 5 - Equipamento utilizado para o ensaio de infiltrabilidade. 
As leituras dos deslocamentos do menisco dentro do tubo capilar foram realizadas em uma relação quadrática de tempo até cessar o fluxo de água. Com os dados referentes ao deslocamento da água no tubo capilar $(\mathrm{cm})$ e a raiz quadrada do tempo $\left(\mathrm{min}^{1 / 2}\right)$, plotou-se um gráfico cujo coeficiente angular da reta representa o coeficiente de sorção ( $\left.\mathrm{s} \mathrm{em} \mathrm{cm} / \mathrm{min}^{1 / 2}\right)$.

Com os valores de perda de massa por imersão (pi) e dos coeficientes de sorção (s), foi possível classificar as amostras analisadas com base no critério de erodibilidade proposto por Nogami \& Villibor (1995). Para os autores, solos considerados erodíveis apresentam a razão pi/s superior a 52.

\section{Ensaio de Inderbitzen}

$\mathrm{O}$ ensaio de Inderbitzen apresenta a concepção de um canal hidráulico em que é medida a perda de solo em amostras cuja superfície coincide com um plano de inclinação variável, por onde passa um fluxo d'água com vazão controlada.

Para a sua realização, foi utilizado o equipamento desenvolvido por Stephan (2010), conforme apresentado na figura 6 , baseado no aparelho proposto inicialmente por Inderbitzen (1961). Foram moldados 3 corpos de prova indeformados de $144 \mathrm{~mm}$ de diâmetro e $44 \mathrm{~mm}$ de altura de cada horizonte pedológico do perfil de corte analisado. As amostras foram ensaiadas nas condições de umidade natural, seca ao ar (por, no mínimo, 72 horas) e inundada (por, no mínimo, 30 minutos).

Em relação às variáveis adotadas para a realização desse ensaio, a inclinação da rampa foi ajustada para um valor de $34^{\circ}$ no intuito de representar a inclinação média do perfil de corte analisado. A vazão de 1,0 L/min foi adotada em função da capacidade de escoamento da rampa e da intensidade média de chuva na região da área de estudo, para um tempo de recorrência de 10 anos e duração de 15 minutos.

O tempo do ensaio foi de 15 minutos e os materiais carreados pelo fluxo superficial foram coletados em intervalos predeterminados de 1, 3, 5 e 15 minutos. $\mathrm{O}$ material carreado foi deixado em repouso para a sedimentação dos grãos e levado à estufa para a determinação da massa de solo seco. Ao fim do ensaio, foram determinadas as perdas acumuladas de massa de solo seco por unidade de área das amostras $\left(\mathrm{g} / \mathrm{cm}^{2}\right)$ para as condições de umidade inicial analisadas.

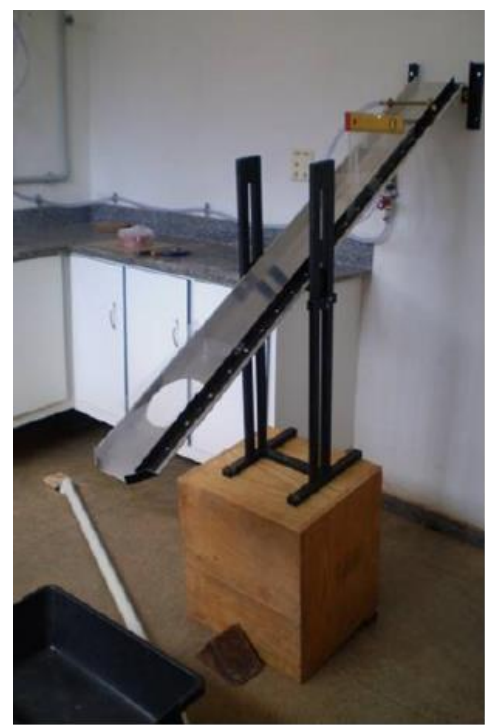

(a) Sistema móvel que permite a variação da inclinação da rampa

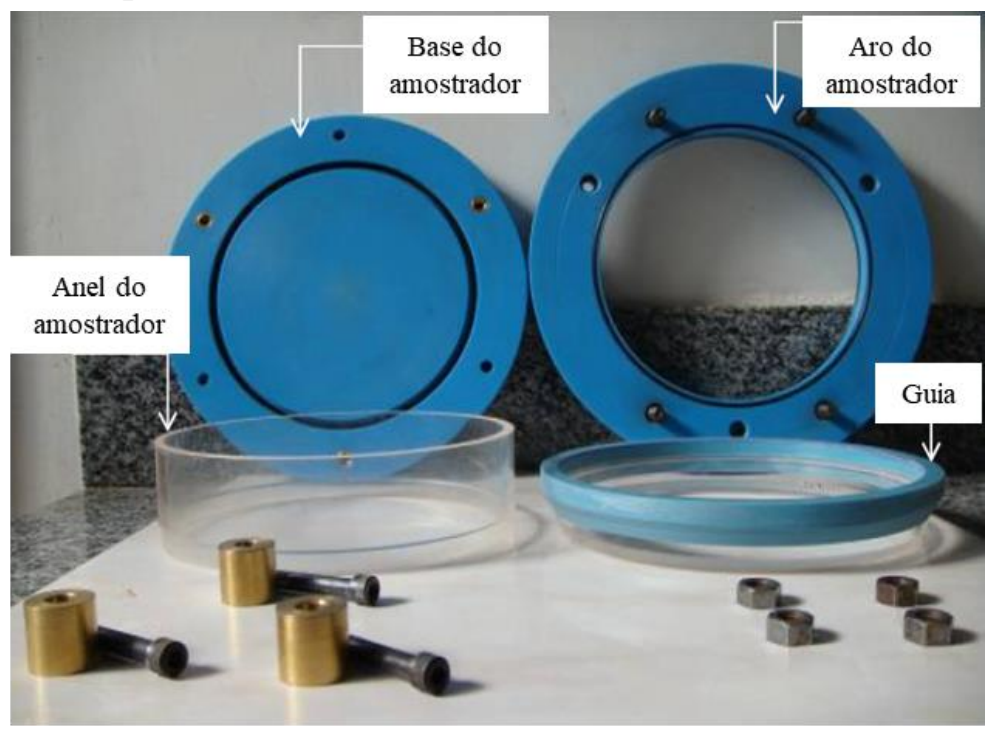

(b) Amostrador circular de $144,0 \mathrm{~mm}$ de diâmetro

Figura 6 - Equipamento utilizado para o ensaio de Inderbitzen (Stephan, 2010).

\section{RESULTADOS E DISCUSSÕES}

\section{Avaliação Baseada na Caracterização Física e Classificação Geotécnica MCT}

Os resultados dos ensaios geotécnicos para a caracterização física e classificação pedológica das amostras de solo analisadas são apresentados na Tabela 1.

Segundo Jacintho et al. (2006), o tamanho das partículas de solo influencia na capacidade de infiltração da água da chuva, interferindo no potencial de escoamento superficial e, consequentemente, na quantidade de solo removido. Apesar dos solos de textura arenosa, normalmente mais porosos, permitirem a rápida infiltração da água da chuva, apresentam baixa 
proporção de partículas argilosas, que atuam como um agente de ligação entre as partículas maiores, indicando sua maior predisposição à remoção do solo pelo escoamento superficial. Em relação a esses critérios, a amostra de solo
BR120-A, por apresentar maior fração de partículas argilosas (67\%), é a mais resistente aos processos erosivos, seguida pelas amostras de solo BR120-C e BR120-B, que apresentam 29\% e $20 \%$ de fração argila, respectivamente.

Tabela 1 - Caracterização física e classificação pedológica das amostras de solo analisadas.

\begin{tabular}{|c|c|c|c|c|c|c|c|c|c|}
\hline \multirow{3}{*}{ Amostra } & \multicolumn{3}{|c|}{$\begin{array}{c}\text { Limites de } \\
\text { Consistência }(\%)\end{array}$} & \multicolumn{5}{|c|}{ Análise Granulométrica (\%) } & \multirow{3}{*}{ Classificação Pedológica } \\
\hline & \multirow{2}{*}{$\mathbf{L L}$} & \multirow{2}{*}{$\mathbf{L P}$} & \multirow{2}{*}{ IP* } & \multicolumn{3}{|c|}{ Areia } & \multirow{2}{*}{ Silte } & \multirow{2}{*}{ Argila } & \\
\hline & & & & Grossa & Média & Fina & & & \\
\hline BR120-A & 81 & 47 & 34 & 5 & 10 & 11 & 7 & 67 & Latossolo vermelho-amarelo \\
\hline BR120-B & 44 & 24 & 20 & 12 & 18 & 15 & 35 & 20 & Saprolítico \\
\hline BR120-C & 70 & 35 & 35 & 1 & 2 & 11 & 57 & 29 & Saprolítico \\
\hline
\end{tabular}

*IP=LL-LP

Ademais, sabe-se que, em geral, solos com maiores índices de plasticidade são menos susceptíveis à erosão. Esse critério reforça que a amostra de solo BR120-B, que apresenta índice de plasticidade igual a $20 \%$, é mais erodível que as amostras de solo BR120-A e BR120-C, cujos índices de plasticidade são $34 \%$ e $35 \%$, respectivamente. Entretanto, Oliveira \& Araújo (2018), ao analisarem a adequabilidade e representatividade de critérios relacionados à granulometria e plasticidade como indicadores de erodibilidade, apontaram que estes métodos, em se tratando de solos tropicais, devem considerar outros fatores como as características estruturais e mineralógicas, visto que essas podem ser determinantes nos processos de desagregação sofrido pelas amostras de solos.

A Tabela 2 apresenta os valores dos parâmetros classificatórios e a classificação geotécnica das amostras de solos analisadas conforme as recomendações da metodologia MCT.

Tabela 2 - Parâmetros classificatórios e classificação geotécnica MCT das amostras de solo analisadas.

\begin{tabular}{c|c|c|c}
\hline Amostra & Coeficiente de deformabilidade - (c') & Índice de laterização - (e') & Classificação - MCT \\
\hline BR120-A & 1,8 & 0,9 & LG' $^{\prime}$ \\
\hline BR120-B & 1,0 & 1,7 & $\mathrm{NS}^{\prime}$ \\
\hline BR120-C & 1,7 & 1,7 & NG' $^{\prime}$ \\
\hline
\end{tabular}

LG' - Solo argiloso laterítico; NS' - Solo siltoso não laterítico; NG' - Solo argiloso não laterítico

Segundo Nogami \& Villibor (1995), o coeficiente de deformabilidade (c') correlacionase, aproximadamente, com a granulometria dos solos. De acordo com esses autores, um c' elevado (acima de 1,5) caracteriza as argilas e solos argilosos. Portanto, as amostras de solos BR120-A e BR120-C, por apresentarem valores de c' equivalentes a 1,8 e 1,7 , respectivamente, se enquadram nessa categoria. Entretanto, para valores de c' de 1,0 até 1,5, como apresentado pela amostra de solo BR120-B, situam-se solos de vários tipos granulométricos, compreendendo as areias siltosas, areias argilosas, argilas arenosas, argilas siltosas, etc.

Já o índice de laterização (e') é responsável por diferenciar o comportamento laterítico, conforme apresentando pela amostra de solo BR120-A ( $\left.\mathrm{e}^{\prime}<1,15\right)$, dos comportamentos não laterítico, observado nas amostras BR120-B e BR120-C (e'> 1,15).

Portanto, considerando-se a classificação geotécnica dos solos com base na metodologia MCT e sua correlação com o potencial de erodibilidade, chega-se à constatação que a amostra de solo BR120-A, pertencente ao grupo LG' (solo argiloso laterítico), será o menos erodível dentre os solos pertencentes aos horizontes pedológicos do perfil de corte rodoviário investigado. Por outro lado, o solo da amostra BR120-B, classificado como de comportamento areno-siltoso não laterítico (NS'), apresenta elevado grau de erodibilidade, enquanto que o solo da amostra BR120-C, de comportamento silto-argiloso não laterítico (NG'), também deve apresentar um elevado grau de erodibilidade, segundo Menezes \& 


\begin{tabular}{|c|c|c|c|}
\hline Amostra & $\begin{array}{c}\text { Condição } \\
\text { de } \\
\text { umidade }\end{array}$ & $\begin{array}{c}\text { Teor de } \\
\text { umidade } \\
\text { inicial (\%) }\end{array}$ & Comportamento da amostra \\
\hline \multirow{2}{*}{\begin{tabular}{c} 
Natural \\
\cline { 2 - 4 }
\end{tabular}} & 23,0 & $\begin{array}{c}\text { Rápida ascensão capilar, ocorrendo baixa expansão da base da amostra nos } \\
\text { minutos iniciais. Ocorreu inchamento da amostra. Durante a total imersão, } \\
\text { iniciou-se a desagregação nas bordas da amostra, permanecendo nestas } \\
\text { condições até o término do ensaio. }\end{array}$ \\
\cline { 2 - 4 } & Seca ao ar & 5,7 & $\begin{array}{c}\text { Rápida ascensão capilar, porém mais lenta quando comparada à condição } \\
\text { natural de umidade. Lenta desagregação das partículas, não desintegrando } \\
\text { completamente, somente nas bordas. }\end{array}$ \\
\cline { 2 - 5 } & Inundada & 62,4 & $\begin{array}{c}\text { Desagregação praticamente inexistente das partículas do solo. Ao final do } \\
\text { ensaio, foi possível observar a formação de fissuras no corpo de prova. }\end{array}$ \\
\hline
\end{tabular}

Figura 7 - Comportamento da amostra do solo BR120-A para as condições de umidade submetidas.

\begin{tabular}{|c|c|c|c|}
\hline Amostra & $\begin{array}{l}\text { Condição } \\
\text { de } \\
\text { umidade }\end{array}$ & $\begin{array}{c}\text { Teor de } \\
\text { umidade } \\
\text { inicial }(\%)\end{array}$ & Comportamento da amostra \\
\hline \multirow{3}{*}{ 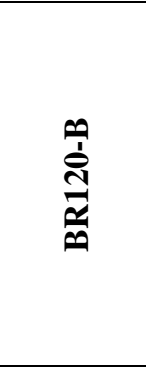 } & Natural & 12,9 & $\begin{array}{l}\text { Total ascensão capilar aos } 30 \text { minutos iniciais, com apresentação de } \\
\text { expansão da base da amostra. Desagregação das partículas já nos minutos } \\
\text { seguintes, chegando à desagregação completa antes de } 2 \text { horas de ensaio. }\end{array}$ \\
\hline & Seca ao ar & 4,7 & $\begin{array}{c}\text { Ascensão capilar mais lenta do que na condição natural, com apresentação } \\
\text { de expansão da base da amostra mais elevada. No decorrer do tempo, há } \\
\text { intensificação da desagregação até desintegrar por completo antes de } 2 \\
\text { horas de ensaio. }\end{array}$ \\
\hline & Inundada & 37,4 & $\begin{array}{c}\text { Lenta e baixa desagregação das partículas do solo e ruptura das bordas do } \\
\text { corpo de prova. }\end{array}$ \\
\hline
\end{tabular}

Figura 8 - Comportamento da amostra do solo BR120-B para as condições de umidade submetidas.

\begin{tabular}{|c|c|c|c|}
\hline Amostra & $\begin{array}{l}\text { Condição } \\
\text { de } \\
\text { umidade }\end{array}$ & $\begin{array}{c}\text { Teor de } \\
\text { umidade } \\
\text { inicial }(\%)\end{array}$ & Comportamento da amostra \\
\hline \multirow{3}{*}{ 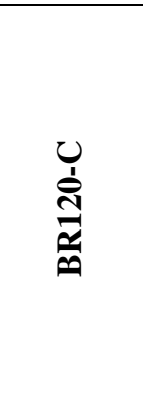 } & Natural & 28,0 & $\begin{array}{c}\text { Ascensão capilar completa aos } 30 \text { minutos iniciais, com expansão } \\
\text { significativa da base. Inchamento da amostra e desintegração dos bordos } \\
\text { da amostra quando imersa por completo, permanecendo nestas condições } \\
\text { até o término do ensaio. }\end{array}$ \\
\hline & Seca ao ar & 1,2 & $\begin{array}{l}\text { Ascensão capilar mais lenta do que na condição natural, maior expansão } \\
\text { da base. Formação de rachaduras e trincas no topo da amostra. Após } \\
\text { completada a imersão, a amostra desintegrou praticamente por completo. }\end{array}$ \\
\hline & Inundada & 55,4 & $\begin{array}{l}\text { Desagregação praticamente inexistente das partículas do solo. Ao final do } \\
\text { ensaio, foi possível observar a formação de fissuras e trincas na lateral da } \\
\text { amostra. }\end{array}$ \\
\hline
\end{tabular}

Figura 9 - Comportamento da amostra do solo BR120-C para as condições de umidade submetidas.

A figura 10 representa o comportamento das amostras ao final do ensaio, para as diferentes condições de umidade inicial analisadas.

Quando comparados os comportamentos das diferentes amostras de solos analisadas, a amostra de solo BR120-B é a que apresenta maior potencial de desagregação, independente da condição de umidade submetida. Esse comportamento pode ser explicado pela maior fração arenosa da amostra (45\%), que indica uma estrutura com vazios interligados, possibilitando a saturação no decorrer do ensaio, com geração de poro pressão positiva que supera a coesão proporcionada pela sucção, com subsequente ruptura estrutural da mesma. Dessa forma, em relação ao potencial de desagregação apresentado, a amostra de solo BR120-B pode ser considerada altamente erodível.

Apesar de a amostra de solo BR120-C, na condição de umidade seca ao ar, apresentar uma maior desestruturação que a amostra de solo BR120-A na mesma condição de umidade, os resultados do ensaio de desagregação não foram conclusivos para se estabelecer uma distinção entre $o$ potencial de desagregação dessas amostras de solo. 


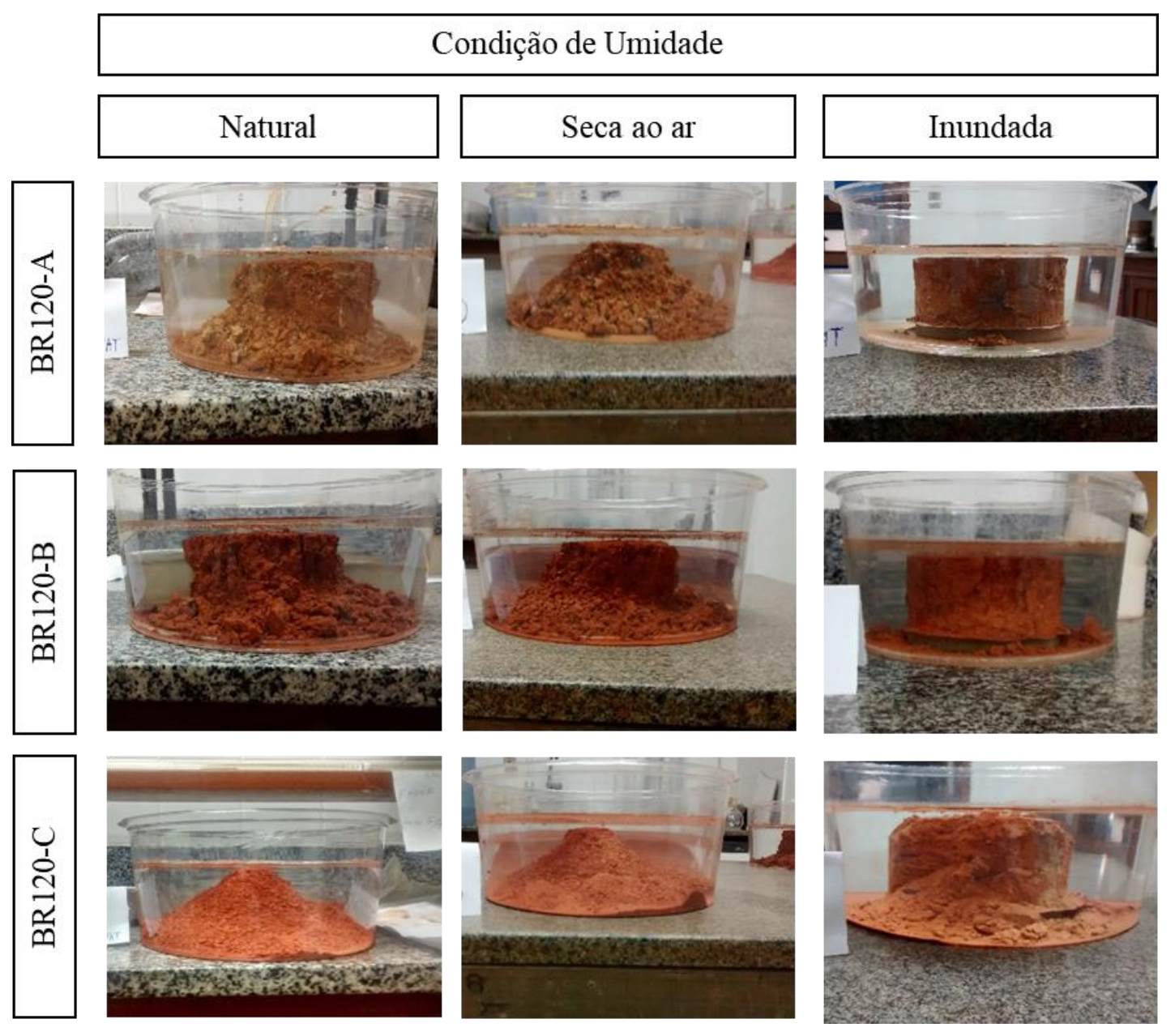

Figura 10 - Amostras após o término do ensaio de desagregação.

Ao se analisar as condições de umidade às quais as amostras foram submetidas, observa-se uma maior resistência à desagregação para as amostras pré-umedecidas (condição inundada). É possível afirmar que quanto menor o grau de saturação, maior é o potencial de desagregação das amostras de solo e, consequentemente, maior a susceptibilidade à erodibilidade. Estudos realizados por Bastos et al. (2000, 2001), Silva et al. (2009), Almeida et al. (2015) e Fonseca et al. (2016) corroboram com os resultados obtidos.

Avaliação Baseada na Metodologia MCT

A Tabela 3 apresenta os resultados obtidos nos ensaios de infiltrabilidade e perda de massa por imersão em água modificado, e as respectivas relações pi/s para as amostras de solos analisadas.

Os valores pouco expressivos dos coeficientes de sorção encontrados para todas as amostras de solos analisadas indicam a reduzida velocidade de ascensão capilar da água nessas amostras. De forma prática, os resultados apontam a baixa capacidade das amostras em infiltrar a água da chuva, o que facilita a formação de fluxo superficial e consequentemente o transporte de partículas.

Tabela 3 - Coeficientes de sorção (s), perda de massa por imersão (pi) e relações pi/s das amostras de solo analisadas.

\begin{tabular}{c|c|c|c|c|c|c|c|c}
\hline \multirow{2}{*}{ Amostra } & \multicolumn{4}{|c|}{ Condição natural } & \multicolumn{4}{c}{ Condição seca ao ar } \\
\cline { 2 - 9 } & $\begin{array}{c}\mathbf{W}^{*} \\
(\boldsymbol{\%})\end{array}$ & $\begin{array}{c}\mathbf{S} \\
\left(\mathbf{c m} / \mathbf{m i n}^{\mathbf{1 / 2}}\right)\end{array}$ & $\begin{array}{c}\mathbf{p i} \\
(\mathbf{\%})\end{array}$ & $\begin{array}{c}\mathbf{p i} / \mathbf{s} \\
\left(\mathbf{c m} / \mathbf{m i n}^{\mathbf{1 / 2}}\right)^{-\mathbf{1}}\end{array}$ & $\begin{array}{c}\mathbf{W} \\
(\boldsymbol{\%})\end{array}$ & $\begin{array}{c}\mathbf{s} \\
\left(\mathbf{c m} / \mathbf{m i n}^{\mathbf{1 / 2}}\right)\end{array}$ & $\begin{array}{c}\mathbf{p i} \\
(\mathbf{\%})\end{array}$ & $\begin{array}{c}\mathbf{p i} / \mathbf{s} \\
\left(\mathbf{c m} / \mathbf{m i n}^{\mathbf{1 / 2}}\right)^{\mathbf{- 1}}\end{array}$ \\
\hline BR120-A & 22,2 & 0,026 & 0,84 & 32,3 & 6,0 & 0,072 & 24,33 & 337,9 \\
\hline BR120-B & 11,9 & 0,025 & 76,73 & $3.069,0$ & 4,0 & 0,036 & 68,84 & $1.912,2$ \\
\hline BR120-C & 28,6 & 0,024 & 2,14 & 89,2 & 1,2 & 0,049 & 73,11 & $1.492,0$ \\
\hline
\end{tabular}

*W: Teor de umidade inicial

A amostra de solo BR120-B apresentou independente da condição de umidade $(76,7 \%$ elevado valor de perda de massa por imersão, para a condição de umidade natural e 68,84\% 
para a condição de umidade quando seca ao ar), razão pela qual ela é potencialmente susceptível à erosão.

As amostras de solo BR120-A e BR120-C apresentaram aumentos significativos de perda de massa por imersão em água em relação à redução do teor de umidade da condição natural para a condição seca ao ar, de $0,8 \%$ para $24,3 \%$ e de $2,1 \%$ para $73,1 \%$, respectivamente. Menezes \& Pejon (2010) destacam a importância da perda de umidade natural dos solos no processo erosivo ao afirmarem que, em geral, quanto mais seco estiver um solo, maior será a perda de massa por imersão. Além disso, segundo esses autores, solos com altas perdas de massa por imersão em água são, em geral, muito susceptíveis à erosão.

Nogami \& Villibor (1995) consideraram erodíveis os solos cuja relação pi/s é superior a 52. Ao aplicar o limite proposto para as amostras de solo analisadas, verifica-se que apenas a amostra de solo BR120-A, na condição de umidade natural, pode ser considerada como não erodível. As amostras de solo BR120-B e BR120 $\mathrm{C}$ são consideradas como erodíveis, independente da condição de umidade inicial.
A avaliação em campo do perfil de corte analisado permitiu observar que o horizonte pedológico do qual foi retirada a amostra a BR120-B é mais erodível do que o horizonte pedológico representativo da amostra de solo BR120-C, enquanto que o horizonte pedológico representativo da amostra BR120-A é o mais resistente aos mesmos processos erosivos. O critério apresentado por Nogami \& Villibor (1995) indica que a amostra de solo BR120-A é a que apresenta menor potencial de erodibilidade, o que condiz com a observação da condição de campo.

Entretanto, esses critérios não distinguem o potencial de erodibilidade das amostras de solo BR120-B e BR120-C, apesar da maior perda de massa por imersão ter sido apresentada pela amostra de solo BR120-B, na condição de umidade natural.

\section{Avaliação Baseada no Ensaio de Inderbitzen}

A tabela 4 apresenta as médias dos valores de perda acumulada de solo por unidade de área das amostras de solos ao final do ensaio de Inderbitzen, para as condições de umidade inicial analisadas.

Tabela 4 - Perda acumulada de solo $\left(\mathrm{g} / \mathrm{cm}^{2}\right)$ para as condições de umidade inicial analisadas.

\begin{tabular}{|c|c|c|c|c|c|c|c|}
\hline \multirow{2}{*}{\multicolumn{2}{|c|}{ Amostra }} & \multicolumn{2}{|c|}{ Natural } & \multicolumn{2}{|c|}{ Seco ao ar } & \multicolumn{2}{|c|}{ Inundado } \\
\hline & & \multirow{2}{*}{$\begin{array}{c}\begin{array}{c}\text { Teor de } \\
\text { umidade } \\
(\%)\end{array} \\
23,1 \\
\end{array}$} & \multirow{2}{*}{$\begin{array}{c}\begin{array}{c}\text { Perda } \\
\text { acumulada } \\
\left(\mathbf{g} / \mathbf{c m}^{2}\right)\end{array} \\
\mathbf{0 , 0 2 1} \\
\end{array}$} & \multirow{2}{*}{$\begin{array}{c}\begin{array}{c}\text { Teor de } \\
\text { umidade } \\
(\%)\end{array} \\
\mathbf{4 , 8} \\
\end{array}$} & \multirow{2}{*}{$\begin{array}{c}\begin{array}{c}\text { Perda } \\
\text { acumulada } \\
\left(\mathrm{g} / \mathrm{cm}^{2}\right)\end{array} \\
\mathbf{0 , 5 6 6} \\
\end{array}$} & \multirow{2}{*}{$\begin{array}{c}\begin{array}{c}\text { Teor de } \\
\text { umidade } \\
(\%)\end{array} \\
72,3 \\
\end{array}$} & \multirow{2}{*}{$\begin{array}{c}\begin{array}{c}\text { Perda } \\
\text { acumulada } \\
\left(\mathrm{g} / \mathrm{cm}^{2}\right)\end{array} \\
\mathbf{0 , 0 4 8} \\
\end{array}$} \\
\hline & Média & & & & & & \\
\hline A & $\begin{array}{l}\text { Desvio } \\
\text { Padrão }\end{array}$ & 0,5 & 0,005 & 0,4 & 0,056 & 1,9 & 0,016 \\
\hline \multirow{2}{*}{$\begin{array}{c}\text { BR120- } \\
\text { B }\end{array}$} & Média & 13,6 & 2,240 & $\mathbf{5 , 0}$ & 2,357 & 33,4 & 0,592 \\
\hline & $\begin{array}{l}\text { Desvio } \\
\text { Padrão }\end{array}$ & 0,3 & 0,358 & 0,3 & 0,124 & 0,4 & 0,410 \\
\hline \multirow{2}{*}{$\begin{array}{l}\text { BR120- } \\
\text { C }\end{array}$} & Média & 26,4 & 0,246 & $\mathbf{1 , 5}$ & $\mathbf{0 , 7 0 1}$ & 56,4 & $\mathbf{0 , 0 1 0}$ \\
\hline & $\begin{array}{l}\text { Desvio } \\
\text { Padrão }\end{array}$ & 0,0 & 0,052 & 0,4 & 0,325 & 0,6 & 0,002 \\
\hline
\end{tabular}

Para todas as amostras de solos analisadas, a maior perda de massa por imersão em água ocorreu para os corpos de prova na condição de umidade seca ao ar, seguida pela condição de umidade natural. O pré-umedecimento das amostras de solos (condição inundada) resultou em uma menor perda de massa dentre as demais condições de umidade inicial. Portanto, é possível afirmar que o potencial de erodibilidade das amostras de solos analisadas aumenta com a redução do teor de umidade inicial.

Segundo Bastos et al. (2001), a menor resistência à erosão de solos secos está relacionada à redução na coesão entre as partículas, provocada pela perda de cimentação e de sucção em virtude do aumento de umidade pelo fluxo d'água superficial. Jacintho et al. (2006), Silva et al. (2009), Aquino et al. (2012) e Almeida et al. (2015) também corroboram com os resultados obtidos e afirmam que a erodibilidade aumenta com o aumento da sucção inicial do solo.

Comparando as amostras de solo representativas de cada horizonte pedológico do perfil de corte analisado, foi possível verificar que os corpos de prova das amostras BR120-B foram os que apresentaram maior perda de massa acumulada, independente da condição de 
umidade analisada. Em condição inversa, os corpos de prova da amostra BR120-A apresentaram menor perda de massa acumulada, nas condições de umidade natural e seca ao ar, seguidos dos corpos de prova da amostra de solo BR120-C.

Para a condição de pré-umedecimento das amostras (condição inundada), a perda de massa acumulada das amostras de solo BR120-A e BR120-C é praticamente inexistente. Esses resultados indicam que o pré-umedecimento dessas amostras reduz drasticamente o desprendimento das partículas pela ação do fluxo de água (Almeida et al., 2015).

Através dos resultados do ensaio de Inderbitzen, foi possível observar que os corpos de prova da amostra de solo denominada BR120$B$ são mais erodíveis que os da amostra BR120-C, e que os corpos de prova da amostra BR120-A foram os mais resistentes à erosão provocada pelo escoamento superficial. Os resultados encontrados são condizentes com as condições pedológicas observadas em campo no perfil de corte analisado.

\section{CONCLUSÃO}

De modo geral, os resultados obtidos através dos ensaios de avaliação indireta de erodibilidade (ensaio de desagregação e ensaios de perda de massa por imersão em água modificado e de infiltrabilidade da metodologia MCT) e de avaliação direta (ensaio de Inderbitzen) se apresentaram satisfatórios para a estimativa do potencial erosivo dos solos representativos dos horizontes pedológicos do perfil de corte rodoviário investigado.

Foi possível observar que as amostras de solo inicialmente secas apresentaram maior potencial de erodibilidade quando saturadas por inundação abrupta (ensaio de desagregação e de perda de massa por imersão em água modificado adaptado da metodologia MCT) ou escoamento superficial de água (ensaio de Inderbitzen). Dessa forma, é possível concluir que o potencial de erodibilidade das amostras de solos analisadas aumenta com a diminuição do grau de saturação.

A avaliação direta do potencial de erodibilidade de solos, por meio do ensaio de Inderbitzen, foi a que melhor representou o comportamento geotécnico dos solos analisados frente aos processos erosivos observados em campo. Os resultados foram condizentes com as condições pedológicas observadas em campo e permitiram estabelecer uma hierarquia para a potencialidade de erodibilidade das amostras de solo analisadas.

Portanto, para o atendimento ao propósito dessa pesquisa, foi observado que o solo da amostra BR120-B é mais erodível que o solo da amostra BR120-C, enquanto que o solo da amostra BR120-A é mais resistente aos mesmos processos erosivos observados em campo e com o menor potencial de erodibilidade.

Os ensaios geotécnicos utilizados nessa pesquisa para a avaliação indireta do potencial de erodibilidade de solos, quando considerados isoladamente, não foram suficientes para estabelecer uma ordenação quanto ao potencial de erodibilidade das amostras de solos representativas dos horizontes pedológicos do perfil de corte analisado. Porém, quando combinados, esses ensaios de avaliação indireta conseguiram representar os diferentes níveis de erodibilidade observados em campo. Dessa forma, o ensaio de desagregação e os da metodologia MCT devem ser utilizados como critérios preliminares na avaliação da potencialidade de erodibilidade de solos.

\section{REFERÊNCIAS}

ABNT - ASSOCIAÇÃO BRASILEIRA DE NORMAS TÉCNICAS. NBR 6457: Amostras de solo - Preparação para ensaios de compactação e ensaios de caracterização. Rio de Janeiro, 2016e, 8 p.

ABNT - ASSOCIAÇÃO BRASILEIRA DE NORMAS TÉCNICAS. NBR 6458: Grãos de pedregulho retidos na peneira de abertura 4,8 mm - Determinação da massa específica, da massa específica aparente e da absorção de água. Rio de Janeiro, 2016d, 10 p.
ABNT - ASSOCIAÇÃO BRASILEIRA DE NORMAS TÉCNICAS. NBR 6459: Solo Determinação do Limite de Liquidez. Rio de Janeiro, 2016b, 5 p.

ABNT - ASSOCIAÇÃO BRASILEIRA DE NORMAS TÉCNICAS. NBR 7180: SoloDeterminação do Limite de Plasticidade. Rio de Janeiro, 2016c, 3 p.

ABNT - ASSOCIAÇÃO BRASILEIRA DE NORMAS TÉCNICAS. NBR 7181: Solo Análise granulométrica. Rio de Janeiro, 
2016a, 12 p.

ALMEIDA

MASCARENHA,

ROMÃO,

P.A.;

M.M.A.;

SALES,

M.M. Erodibilidade de solos tropicais não saturados nos municípios de Senador Canedo e Bonfinópolis (GO). Geociências, v.34, n. 3, p. 441-451, 2015.

AQUINO, R.F.; SILVA, L.M.N.; FREITAS, D.A.F.; CURI, N.; AVANZI, J.C. Soil losses from Typic Cambisols and Red Latosol as related to three erosive rainfall patterns. Revista Brasileira de Ciência do Solo, v. 37, p. 213-220, 2012.

BASTOS, C.A.B.; MILITITSKY, J.; GEHLING, W.Y.Y. A avaliação da erodibilidade dos solos sob o enfoque geotécnico pesquisas e tendências. Teoria e Prática na Engenharia Civil, v. 1, p. 17-25, 2000.

BASTOS, C.A.B.; MILITITSKY, J.; GEHLING, W.Y.Y. Estudo sobre a erodibilidade de solos residuais não saturados a partir de propriedades geomecânicas. Teoria e Prática na Engenharia Civil, v. 2, p. 9-18, 2001.

DNER - DEPARTAMENTO NACIONAL DE ESTRADAS DE RODAGEM. ME 258: Solos Compactados com Equipamentos Miniatura

- Mini-MCV. Rio de Janeiro, 1994c, 14 p.

DNER - DEPARTAMENTO NACIONAL DE ESTRADAS DE RODAGEM. CLA 259: Classificação de Solos Tropicais para Finalidades Rodoviárias Utilizando Corposde-prova Compactados em Equipamentos Miniatura. Rio de Janeiro, 1996, 6 p.

DNER - DEPARTAMENTO NACIONAL DE ESTRADAS DE RODAGEM. ME 256: Solos Compactados com Equipamentos Miniatura - Determinação da Perda de Massa por Imersão. Rio de Janeiro, 1994d, 6 p.

DNER - DEPARTAMENTO NACIONAL DE ESTRADAS DE RODAGEM. PRO 002: Coleta de amostras indeformadas de solos. Rio de Janeiro, 1994a, 12 p.

DNER - DEPARTAMENTO NACIONAL DE ESTRADAS DE RODAGEM. PRO 003: Coleta amostras deformadas de solos. Rio de Janeiro, 1994b, 4 p.

FONSECA, L.D.M.; LANI, J.L.; FERNANDES FILHO, E.I.; MARQUES, E.A.G.; FERREIRA, W.P.M. Avaliação da erodibilidade de um cambissolo de Juiz de Fora, Minas Gerais. Geotecnia, v. 136, p. 143-156, 2016.

INDERBITZEN, A.L. An erosion test for soils.
Materials Research \&Standards, v. 1, n. 1, p. 553-554, 1961.

JACINTHO, E.C.; CAMAPUM DE CARVALHO, J.; CARDOSO, F.B.F.; SANTOS, R.M.M.; GUIMARÃES, R.C.; LIMA, M.C.G. Solos tropicais e o processo erosivo. In: CAMAPUM DE CARVALHO, J.; SALES, M.M.; SOUZA, N.M.; MELO, M.T.S. (Organizadores). Processos erosivos no centro-oeste brasileiro. $1^{\text {a }}$ ed., Brasília: FINATEC, p. 93-147, 2006.

MENEZES, M.B.M. \& PEJON, O.J. Análise da influência do teor de umidade na absorção d'água e sucção dos solos em estudos de erodibilidade. Geociências, v. 29, n. 2, p. 211-228, 2010.

NOGAMI, J.S. \& VILLIBOR, D.F. Pavimentação de baixo custo com solos lateríticos. São Paulo: Villibor, 1995, 240 p.

OLIVEIRA, F. \& ARAÚJO, R.C. Uso de parâmetros geotécnicos como indicadores da erodibilidade dos solos. Geotecnia, v 142, p. 63-75, 2018.

SANTOS, R.M.M. Caracterização geotécnica e análise do processo evolutivo das erosões no município de Goiânia. Brasília, 1997. 120 p. Dissertação (Mestrado em Geotecnia) Departamento de Engenharia Civil, Universidade de Brasília.

SILVA, A.M.; SILVA, M.L.N.; AVANZI, J.C.; FERREIRA, M.M. Erosividade da chuva e erodibilidade de cambissolo e latossolo na região de Lavras, sul de Minas Gerais. Revista Brasileira de Ciência do Solo, v. 33, p. 18111820, 2009.

SILVA, T.O.; NASCIMENTO, R.C.; FARIA, J.W.S.; PITANGA, H.N.; LIMA， D.C.; SANT'ANNA, G.L. Soil susceptibility to accelerated hydric erosion: geotechnical evaluation of cut slopes in residual soil profiles. Acta Scientiarum. Technology, v. 37, p. 331337, 2015.

STEPHAN, A.M. Análise de processos erosivos superficiais por meio de ensaios de Inderbitzen. Viçosa, 2010, 165 p. Tese (Doutorado em Geotecnia) - Departamento de Engenharia Civil, Universidade Federal de Viçosa.

Submetido em 7 de fevereiro de 2019 Aceito para publicação em 15 de abril de 2020 